\title{
Efeitos da insuficiência pluviométrica na cobertura vegetal da planície estuarina do complexo Piranhas-Assú (Nordeste do Brasil)
}

\author{
Effects of pluviometric insufficiency in the plant coverage of the stuarine plain of the \\ Piranhas-Assú complex (Northeast of Brazil)
}

MEDEIROS $^{1}$, D. H. M.; PINHEIRO ${ }^{2}$, L. S.

davidgeo.ambiental@yahoo.com.br

\begin{abstract}
Resumo
Esta pesquisa objetiva identificar as variações da cobertura vegetal entre os anos de 2012 e 2015 no complexo estuarino do Rio Piranhas-Assú (RN). Foi realizado balanço hídrico, a partir de dados de precipitação, temperatura e evapotranspiração potencial. Foram obtidas imagens do LandSat 8 para monitoramento temporal da cobertura vegetal através da técnica de SAVI. O balanço hídrico ratificou a propensão do ambiente aos efeitos da deficiência hídrica, mesmo em períodos de maior precipitação, com o maior déficit hídrico registrado em agosto (2012) e dezembro (2015), atingindo aproximadamente $-190 \mathrm{~mm}$. Alguns trechos com predominância de solo exposto em 2015 eram ocupados predominantemente por vegetação em 2013. Para os fragmentos de vegetação observou-se diminuição de até 41,8\%, aumentando a exposição direta dos solos. Portanto, a metodologia utilizada apresentou-se como alternativa viável para estudos relacionados às variações temporais da cobertura vegetal.
\end{abstract}

Palavras-chave: cobertura vegetal; estuário; semiárido.

\begin{abstract}
This research aims to identify the variations of the vegetation cover between the years 2012 and 2015 in the estuary complex of the Piranhas-Assú River (RN). A water balance was performed, based on precipitation, temperature and potential evapotranspiration data. LandSat 8 images were obtained for temporal monitoring of vegetation cover using the SAVI technique. The water balance ratified the environmental propensity to the effects of water deficiency, even in periods of higher precipitation, with the highest water deficit recorded in august (2012) and december (2015), reaching approximately $-190 \mathrm{~mm}$. Some sections with predominance of soil exposed in 2015 were predominantly occupied by vegetation in 2013 . For the fragments of vegetation, a $41.8 \%$ decrease was observed, increasing the direct exposure of the soils. Therefore, the methodology used was presented as a viable alternative for studies related to the temporal variations of the vegetation cover.
\end{abstract}

Keywords: vegetal cover; estuary; semiarid.

\section{INTRODUÇÃO}

As condições climáticas semiáridas em algumas bacias hidrográficas do Rio Grande do Norte proporcionam taxas de evapotranspiração potencial maiores do que as precipitações, determinando níveis de escoamento superficial praticamente desprezíveis, e tornando as planícies estuarinas dominadas por as águas de origem marinha durante os períodos de estiagens (IDEMA, 2002; RAMOS E SILVA, 2004; MEDEIROS, 2016).

Nessa região o sistema climático apresenta forte entrada de energia solar com regime térmico uniforme, marcado por temperaturas elevadas e pequenas variações ao longo do ano; índices de

\footnotetext{
${ }^{1}$ David Hélio Miranda de Medeiros, Programa de Pós-Graduação em Ciências Marinhas Tropicais/Laboratório de Oceanografia
} Geológica, Instituto de Ciências do Mar (LABOMAR), Universidade Federal do Ceará, Fortaleza-CE, Brasil 
precipitações relativamente escassos e extremamente irregulares entre anos (NIMER, 1989; MEDEIROS, 2016). A complexidade do semiárido deriva das grandes diferenciações pluviométricas (AB' SABER, 1974), que associadas às demais variáveis climatológicas, determinam o déficit entre precipitação e evaporação superior a $2000 \mathrm{~mm} / \mathrm{ano}$, conforme mostram estudos na região de Macau (RN) (DINIZ; VASCONCELOS, 2016).

Essa é uma condição adversa para sustentabilidade estuarina, que tem na maioria dos tributários o déficit de afluência contínua significativa, provavelmente em resultado da maioria dos cursos d'água da bacia apresentar caráter intermitente e alguns dotados de barramentos, como mostram estudos nos estuários do Rio Apodi-Mossoró (MEDEIROS, 2016; VALLE-LEVINSON; SCHETTINI, 2016), Catu (PINHEIRO; MORAIS; 2010), Coreaú (VALENTIM, 2016), Malcozinhado (PINHEIRO, 2003), Pirangi (SCHETTINI et al., 2017).

Essas características impõem restrições ao desenvolvimento florístico, uma vez que na medida em que diminui a umidade do solo, ocorrem restrições à transferência de água para a atmosfera, que passa a depender não somente das condições meteorológicas, mas também do sistema radicular das plantas, bem como de outras características, como o estado fitossanitário das mesmas (BERLATO; MOLION, 1981; TUCCI, 2007; MEDEIROS, 2016).

Nesse sentido, observa-se a necessidade de discussão de aspectos ligados às respostas florísticas em ambientes estuarinos do semiárido, diante da insuficiência e irregularidade das chuvas, associada a elevadas taxas de evapotranspiração potencial. Dessa forma, esta pesquisa objetiva identificar as variações da cobertura vegetal entre os anos de 2012 e 2015.

\section{Área de estudo}

O presente estudo foi desenvolvido no complexo estuarino do Rio Piranhas-Assú (RN), situado entre os municípios de Carnaubais, Macau, Pendências e Porto do Mangue (Figura 1). Essa área consiste numa zona costeira formada principalmente por planícies de inundações fluviomarinhas, ecossistemas de manguezais, campos de dunas e praias arenosas (SILVA; AMARO, 2008).

No geral, os níveis médios de precipitações anuais são inferiores a $600 \mathrm{~mm}$ (DINIZ; PEREIRA, 2015; DINIZ; VASCONCELOS, 2016), sendo os meses de fevereiro a maio como os mais úmidos, com segundo semestre de índices pluviométricos inferiores a $10 \mathrm{~mm}$. Os valores médios anuais de evaporação são de $2.077,6$ mm, com insolação em torno de 2.600 horas/ano e 7,2 horas/diárias (SOARES, 2012).

A temperatura média anual na região é $26,8^{\circ} \mathrm{C}$. Entre os meses de setembro a dezembro apresentam-se os níveis mais elevados de temperatura $\left( \pm 34^{\circ} \mathrm{C}\right)$. Os meses de junho a agosto 
compreendem o trimestre com temperaturas médias mais baixas $\left( \pm 26^{\circ} \mathrm{C}\right)$. A amplitude térmica diária normalmente está entre $8^{\circ}$ e $10^{\circ} \mathrm{C}$, com umidade relativa do ar com média em torno de $66 \%$ (AMARO et al., 2002).

Os ventos são frequentes com direção predominante entre E, SE e NE. Entre março e julho a velocidade média mensal varia de 4,2 a $5,5 \mathrm{~m} / \mathrm{s}$; e entre agosto a dezembro as velocidades são mais intensas, podendo atingir entre 7,0 a 9,2 m/s (AMARO; COSTA, 2012; DINIZ; VASCONCELOS, 2016).

As drenagens locais seguem a orientação NE e NW, associadas ao controle estrutural da área (SILVA; AMARO, 2008; MAIA; BEZERRA, 2013); não apresentam afluência contínua significativa pela maioria dos tributários. Esse é uma característica resultante da maioria dos cursos d'água da bacia apresentar caráter intermitente, como característico da maioria dos rios do semiárido (PINHEIRO; MORAIS, 2010; MEDEIROS, 2016; VALENTIM, 2016; VALLE-LEVINSON; SCHETTINI, 2016; SCHETTINI et al., 2017).

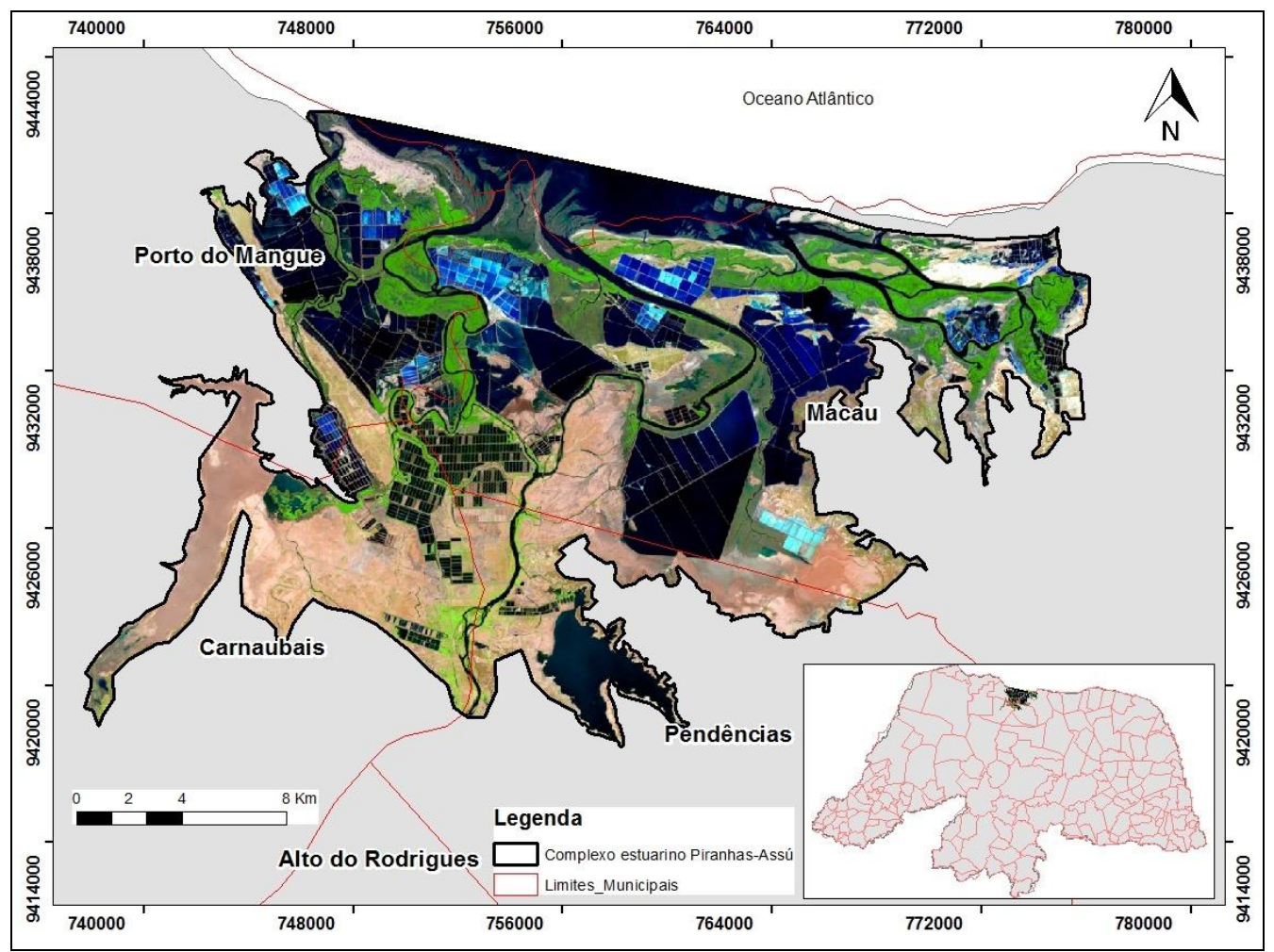

Figura 1: Localização do complexo estuarino do Rio Piranhas-Assú (RN).

Do ponto de vista da diversidade paisagística, na porção costeira o modelamento das formas de relevo é resultante da ação constante dos processos do meio físico, tais como condições climáticas, variações do nível do mar, natureza das sequências geológicas, atividades neotectônicas 
e suprimento de sedimentos carreados pelos rios e oceano (CASTRO et al., 2003; COSTA, et al. 2006; GRIGIO et al., 2011).

Como produto das características ambientais regionais (COSTA et al., 2014), essa área tem importante potencial econômico, haja vista o desenvolvimento secular da atividade salineira nas extensas várzeas hipersalinas, atividades de extração de petróleo, carcinicultura e turismo (MEDEIROS et al., 2014).

\section{METODOLOGIA}

\section{Estimativa do balaço hídrico}

Para estimar o balanço hídrico foi usada a metodologia propostas Rolim et al. (1998), baseado em um programa para cálculos de balanço hídrico $(\mathrm{BH})$, adotando-se o método de, que realiza contabilização do suprimento natural de água ao sistema, pela chuva (P), e da demanda atmosférica, pela evapotranspiração potencial (ETP), e com um nível máximo capacidade de água disponível (CAD). Por esse método, o balanço hídrico fornece estimativas da evapotranspiração real (ETR), da deficiência hídrica (DEF), do excedente hídrico (EXC), como também pela dada potencialidade de armazenamento de água no solo (ARM).

Para tanto, foram empregados dados normais de temperatura, evapotranspiração potencial e precipitação pluviométrica mensais, a partir do banco de informações da estação meteorológica de Macau (RN), pertencente ao INMET (Instituto Nacional de Meteorologia). Para a capacidade de água disponível (CAD), utilizou-se o valor de $100 \mathrm{~mm}$, por ser o nível normalmente empregado para classificação climática, de acordo com Vianello \& Alves (2006) apud Portilho et al. (2011).

Para definição do período de estudo, foram observados a sequência de anos com condições de semiaridez mais severas. Dessa forma, os anos de 2012 a 2015 foram definidos para o presente estudo, uma vez que houve predomínio do déficit hídrico no semiárido brasileiro (MARENGO et al., 2016), como na porção setentrional do Rio Grande do Norte, onde o volume de chuvas foram inferiores as médias normais climatológicas: 507,2 mm em Macau e 787,9 em Mossoró (INMET, 2009). Cabe destacar que o ano de 2011 serviu como delimitador para o recorte temporal, visto que os acumulados pluviométricos foram superiores aos níveis normais (Figura 2). 


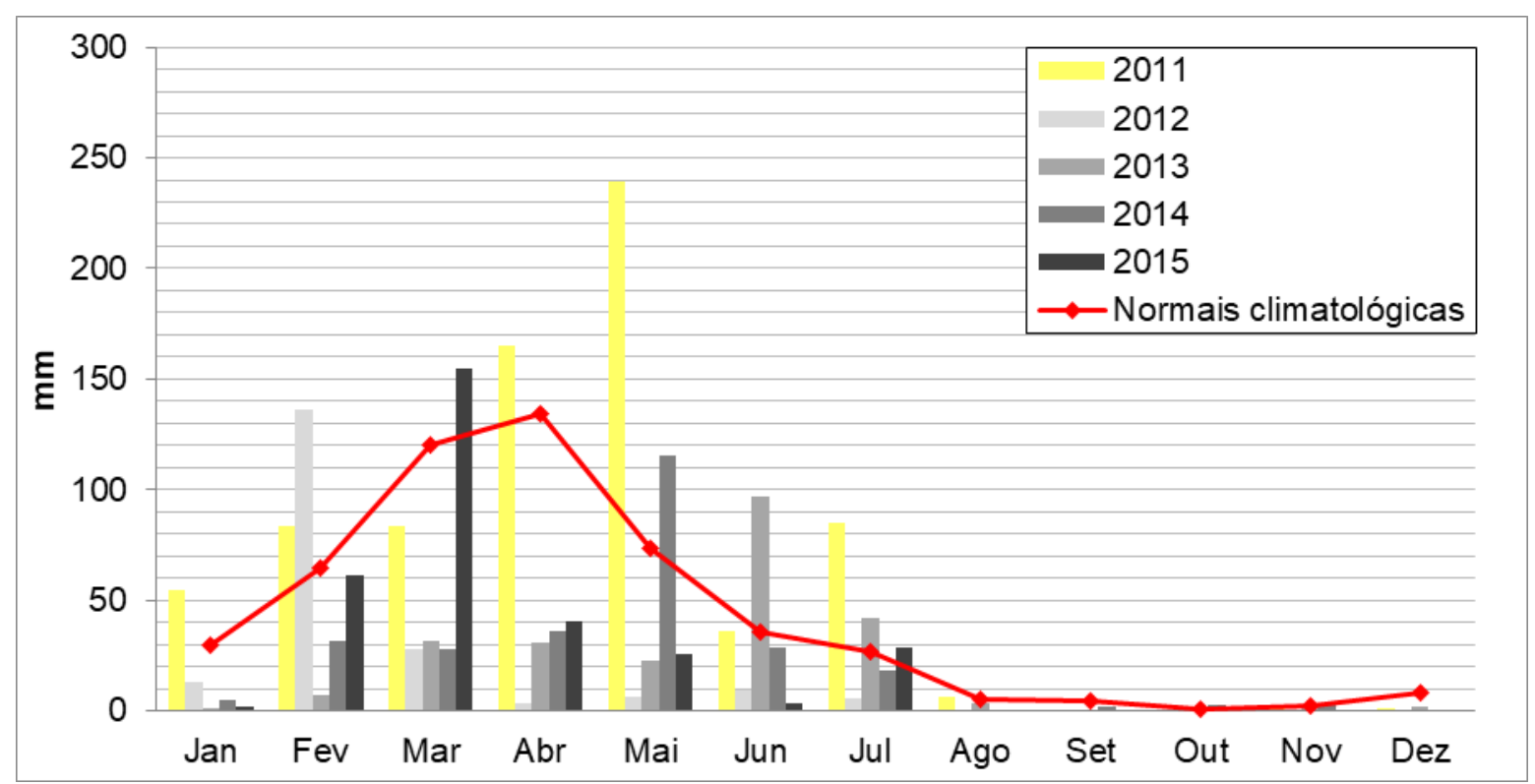

Figura 2: Precipitação pluviométrica acumulada mensal dos anos de 2011 a 2015 e normais pluviométricas (1961-1990). Fonte: Adaptado de INMET.

\section{Monitoramento da cobertura vegetal}

Objetivando integrar as condições hídricas ao aspecto florístico foi realizada a análise da variação temporal da cobertura vegetal, através do Índice de Vegetação Ajustada ao Solo (SAVI). Esse índice utiliza duas características espectrais da vegetação: a intensa absorção da clorofila na região do vermelho e sua intensa reflexão no infravermelho próximo.

Foram utilizadas bandas (banda 04 - vermelho e a banda 05 - infravermelho) do LandSat 8 OLI/TIRS, obtidas no site da USGS (United States Geological Survey), optando pelo critério de seleção baseado nas cenas com boa qualidade, não comprometidas por cobertura de nuvens na área desejada e com períodos (mês) de coleta correspondentes a mesma estação climática. Dessa forma, as cenas escolhidas para este trabalho foram a LC82150642013232LGN00, com data de 20 de agosto de 2013, e LC82150642015206LGN00 de 25 de julho de 2015.

Inicialmente as imagens foram submetidas a um processo de reprojeção, sendo adicionado e transformado a sua posição (geometria) para um sistema de coordenadas mais adequado. Foi aplicada a transformação de UTM (Universal Transversa de Mercator) com Datum WGS 84 Norte para UTM com Datum de referência indicado para o SIRGAS2000 Zona 24 Sul. As imagens foram submetidas ao processo de recorte para o enquadramento da área de estudo, através do uso da ferramenta CLIP (Cortar) do software ArcGis 10, por meio de um vetor delimitador da área do complexo estuarino do Rio Piranhas-Assú (RN).

Em seguida, foi realizada a correção atmosférica das imagens, sendo utilizado o modelo Dark Object Subtraction (DOS) também conhecido como subtração de pixel escuro (SPE), que, segundo ANDRADE (et al., 2010) consiste em corrigir o espalhamento atmosférico e estimar a interferência 
atmosférica a partir dos números digitais (ND) das imagens. Após a etapa de correção atmosférica, as imagens pré-processadas tornaram-se aptas para analisar as principais feições da área a partir da composição RGB com as bandas 6, 5 e 4 (Figura 3), assim como para aplicação da álgebra de mapas (SAVI) (ALVARENGA; MORAES, 2014).
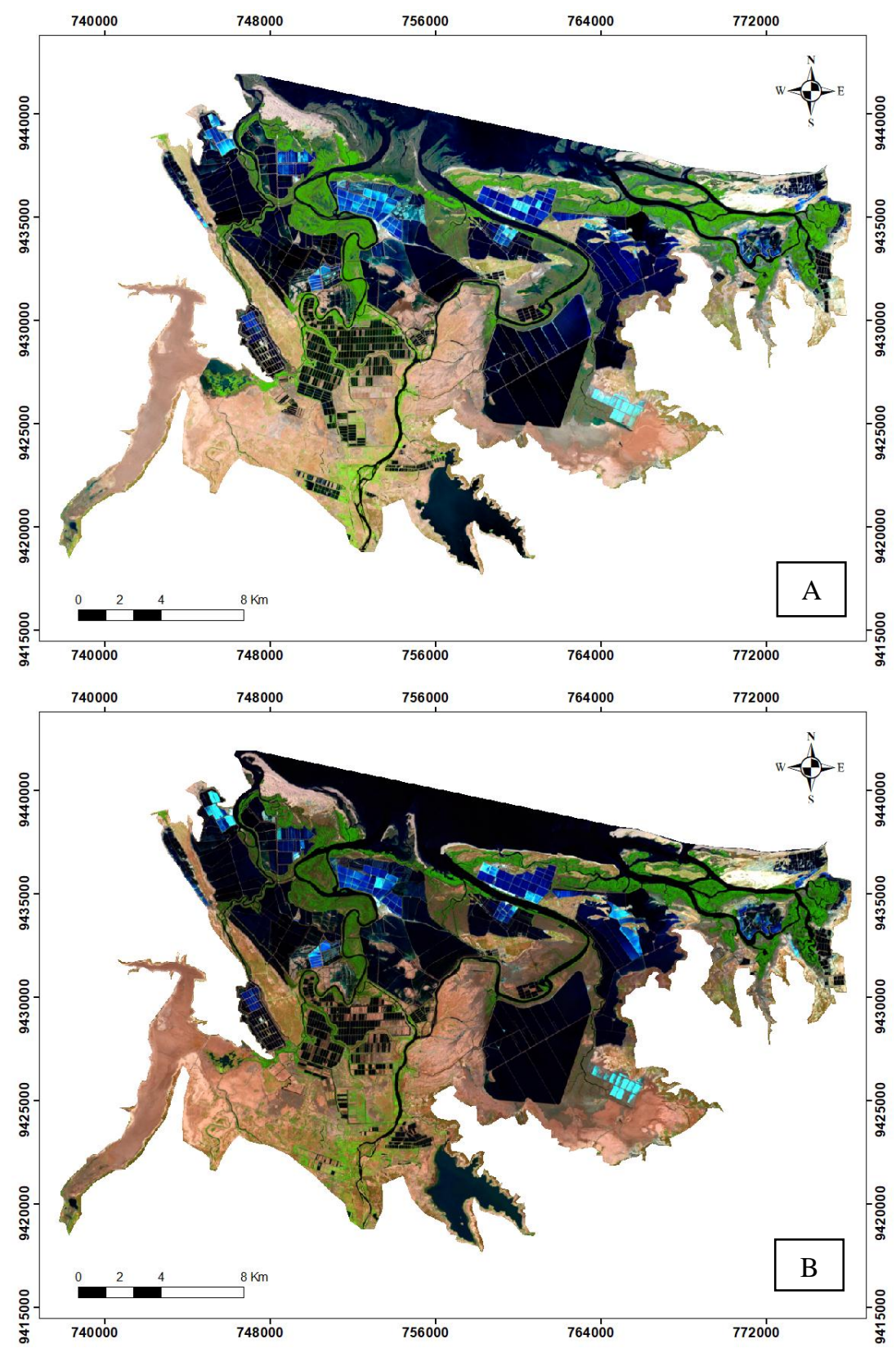

Figura 3: Composição RGB bandas 6-5-4, do ano de 2013 (A) e 2015 (B).

O SAVI é obtido pela multiplicação de $1+$ L pela razão entre a diferença da reflectância do infravermelho próximo (NIR) pela reflectância do vermelho (R), dividida, respectivamente, pela soma das mesmas + “L”. Para este índice, Huete (1988) propôs a expressão (Equação 1). 


$$
\mathrm{SAVI}=(1+\mathrm{L}) \mathrm{x}(\mathrm{NIR}-\mathrm{R}) /(\mathrm{NIR}+\mathrm{R}+\mathrm{L})
$$

Segundo Huete (1988), a constante L, pode apresentar valores de 0 a 1, variando segundo a própria biomassa. Os valores ótimos de $\mathrm{L}$ são: $\mathrm{L}=1$ (para baixas densidades de vegetação) $\mathrm{L}=0,5$ (para médias densidades de vegetação) $L=0,25$ (para altas densidades de vegetação). Em geral $o$ fator $\mathrm{L}=0,5$ é mais comumente utilizado, uma vez que engloba uma maior variação de condições de vegetação (HUETE, 1988; PONZONI; SHIMABUKURO, 2009; VIGANÓ et al., 2011). Portanto, sendo o valor escolhido para aplicação da equação com as imagens selecionadas.

Para os produtos cartográficos obtidos, foram atribuídos os mesmos intervalos temáticos para as classes definidas. Dessa forma, os níveis de verde expressam valores que representam os mais altos índices de vegetação (escuro), e com espécies esparsas e herbáceas (claro). Em amarelo e laranja representam baixos índices de vegetação, com tendência ao domínio de solos expostos. Em vermelho correspondem a alvos urbanos, empreendimentos salineiros e de carcinicultura.

Após essa etapa, as imagens SAVI geradas foram submetidas à técnica de segmentação visando extrair a cobertura vegetal (rala, esparsa e densa), sendo posteriormente realizado a classificação supervisionada. Por fim, foram calculadas as áreas e estabelecidas às taxas de regressão da cobertura vegetal.

Cabe destacar que o processamento digital das imagens foi realizado no software SPRING 5.2 (CÂMARA et al., 1996), sendo gerado shapefile dos produtos gráficos. Para a álgebra de mapas e procedimentos que necessitam de uma plataforma de Sistema de Informação Geográfica (SIG) foi utilizado o software ArcGis 10 (Educational Edition EVA866900120).

\section{RESULTADOS E DISCUSSÃO}

O balanço hídrico climatológico ratificou a propensão do ambiente aos efeitos da deficiência hídrica (DEF). Durante todo o período permaneceram taxas de precipitação pluviométrica menor do que a evapotranspiração potencial (P < ETP) (Figura 4). Nos meses agosto em 2012, assim como em dezembro de 2015, foram caracterizados pelo maior nível de déficit hídrico, atingindo aproximadamente $-190 \mathrm{~mm}$. No geral, a deficiência hídrica acumulada para ano de 2012 foi de 1.784,8 mm, -1.829,8 em 2013, o ano de 2014 com -1.735 mm e -1.708,2 mm em 2015.

A irregularidade e intensidade interanual das chuvas, apresentou relativa influência pontual para diminuição dos níveis de deficiência, conforme observado para o mês de fevereiro, em 2012 e março de 2015. Entretanto, mesmo com a presença de chuvas nesse período, permaneceram índices de deficiência de umidade, testemunhando a influência dos altos níveis de insolação e temperatura 
para o aumento das taxas de evapotranspiração potencial ao ponto de superar as precipitações ocorridas.
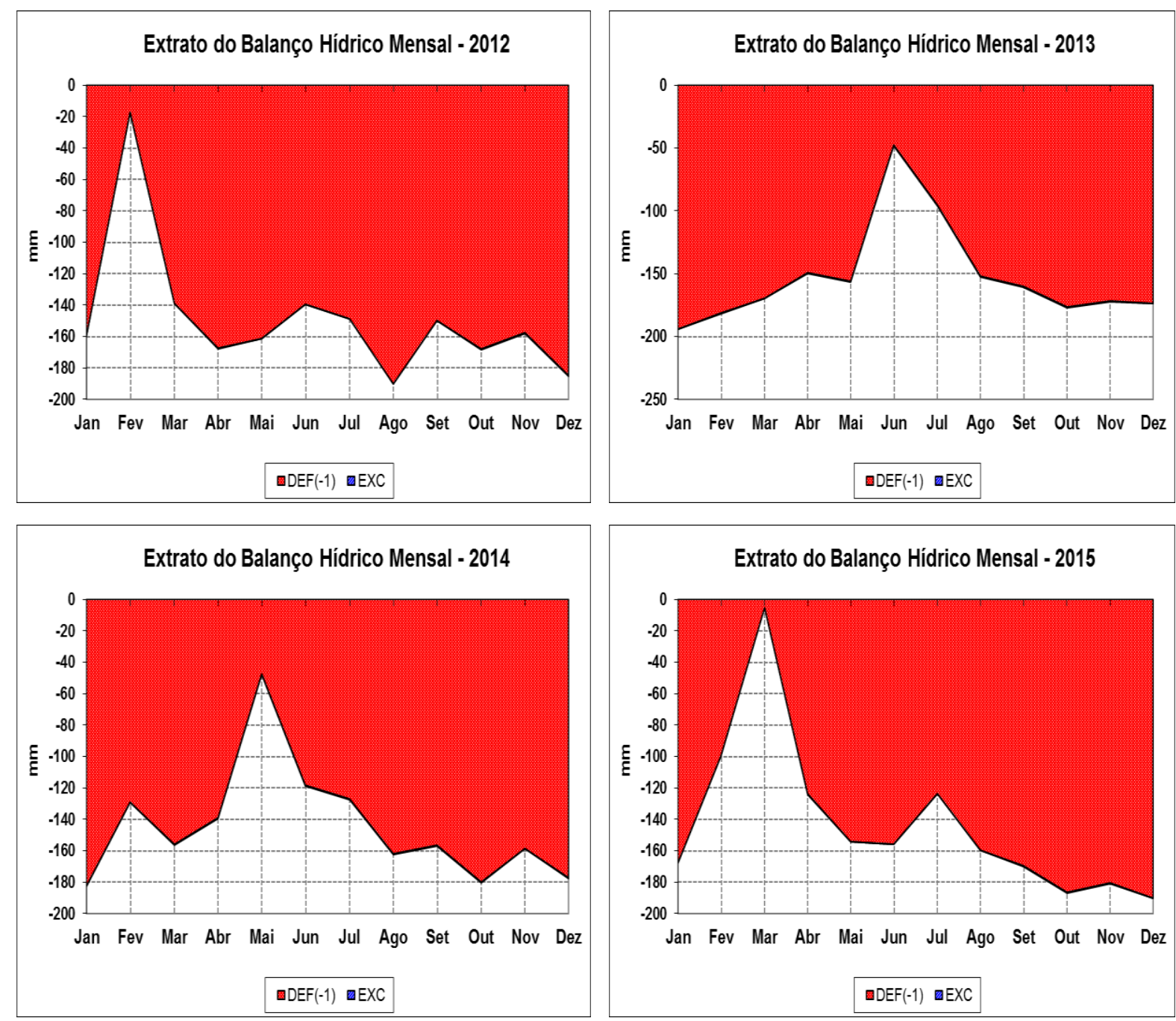

Figura 4: Balanço hídrico climatológico para o município de Macau (RN), entre os anos de 2012 a 2015.

Os coeficientes obtidos da técnica SAVI apresentaram diferenças para os anos de 2013 e 2015. As áreas predominantemente ocupadas por vegetação (verde claro) em 20 de agosto de 2013 (Figura 5) passaram a apresentar solo exposto (amarelo) em 25 de julho de 2015 (Figura 6), principalmente na porção central e $3^{\circ}$ quadrante (oeste-sul). Nas regiões mais próximas a foz, também ocorreu o aumento de trechos para domínio de solos expostos em ambientes anteriormente cobertos por vegetação. Para algumas áreas com fragmentos de vegetação de porte arbóreo (verde escuro), foi observada uma tendência de evolução para diminuição da cobertura vegetal, assim como exposição direta dos solos.

Como as reservas superficiais estão expostas diretamente à radiação solar, o seu aquecimento é máximo, conduzindo para elevada taxa de evaporação líquida. Nesse sentido, o estresse hídrico 
provocou alteração interanual da vegetação (rala, esparsa e densa), que reduziu aproximadamente 41,8\% do ano de 2013 para 2015.

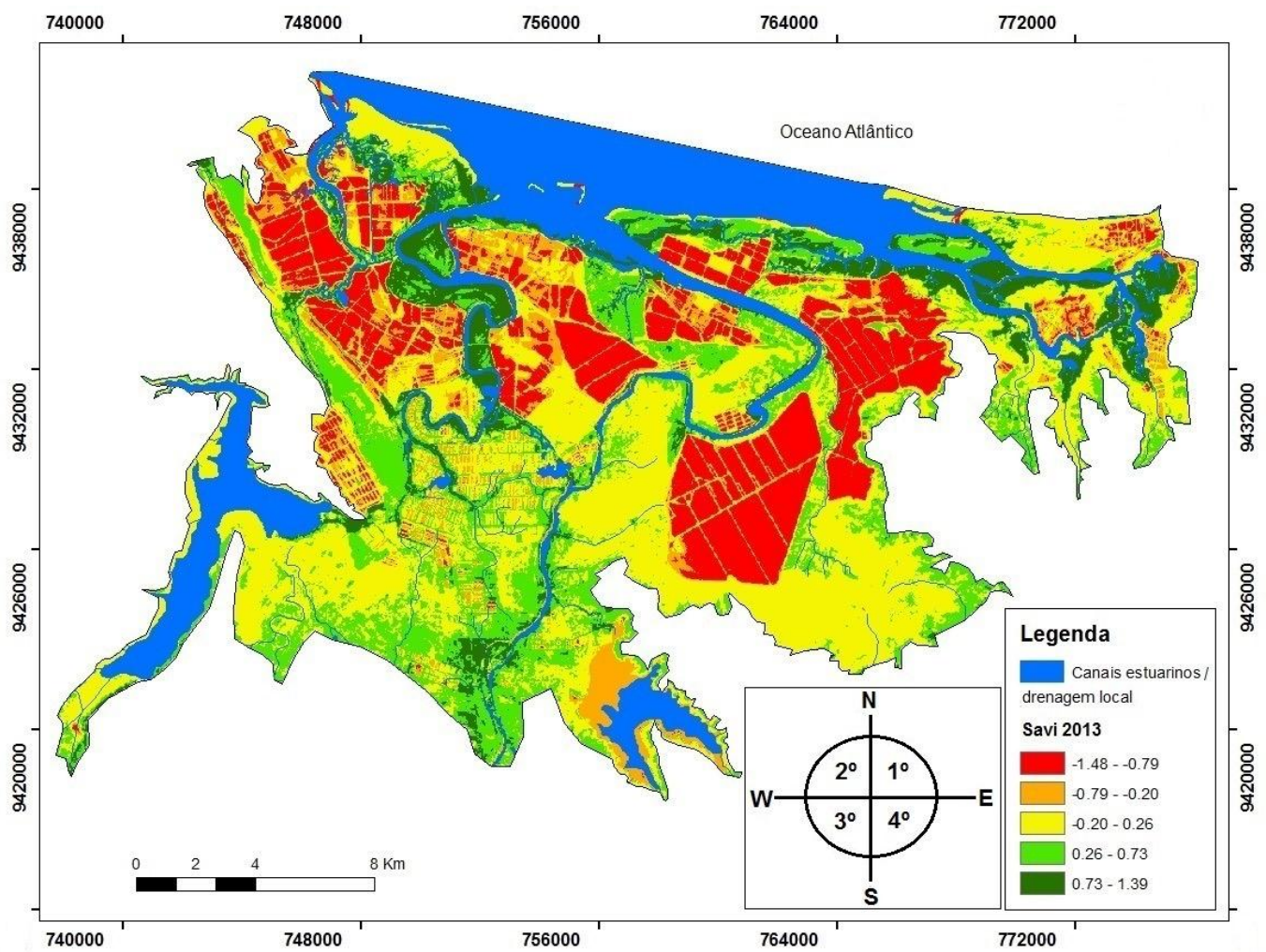

Figura 5: SAVI do ano de 2013, do complexo estuarino do Rio Piranhas-Assú (RN).

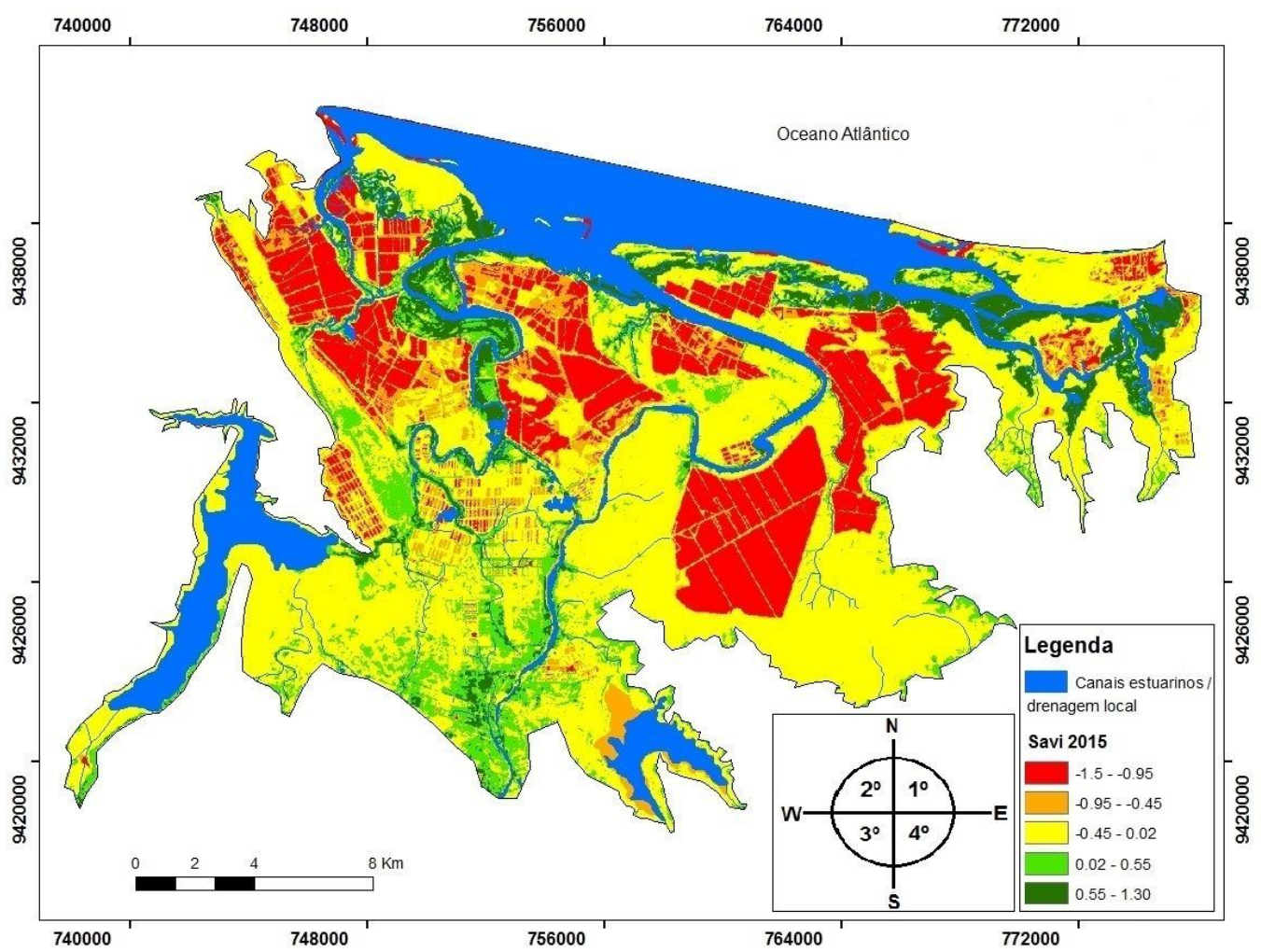

Figura 6: SAVI do ano de 2015, do complexo estuarino do Rio Piranhas-Assú (RN). 
A continuidade dessas características tornou-se uma condicionante para hipersalinidade na maioria dos estuários da região, sobretudo durante os períodos de estiagem (MEDEIROS, 2016), sendo comum a ocorrência de extensas planícies hipersalinas nessa zona litorânea (COSTA et al., 2013; MEDEIROS, op. cit.). Nesse contexto, a salinização afeta diretamente os constituintes naturais do solo e da água, podendo contribuir na degradação dos ecossistemas, principalmente diminuindo a cobertura vegetal (FERREIRA et al., 2008).

Cabe destacar que para a presente pesquisa não foram considerados processos ligados ao extrativismo vegetal. Nessa região os manguezais e caatinga são as principais unidades fitoecológicas (AMARO; COSTA, 2012). Os manguezais são integralmente protegidos pela Lei $\mathrm{n}^{\circ}$. 12.651/2012 do Código Florestal do Brasil, ao passo que a supressão de vegetação nativa da caatinga é regulada por órgãos ambientais competentes.

\section{CONSIDERAÇÕES FINAIS}

Houve predomínio de deficiência hídrica, decorrente da insuficiência e irregularidade das chuvas, associada a elevadas taxas de evapotranspiração potencial. Embora a ocorrência de aumento pontual das precipitações em alguns meses, a continuidade de elevados níveis de insolação e temperatura foram determinantes para alta evapotranspiração, corroborando a manutenção das condições de insuficiência hídrica em períodos de maior umidade. Como consequência, o déficit acumulado para ano de 2012 foi de $-1.784,8 \mathrm{~mm},-1.829,8 \mathrm{em} \mathrm{2013,} \mathrm{o} \mathrm{ano} \mathrm{de} 2014 \mathrm{com}-1.735 \mathrm{~mm}$ e -1.708,2 mm em 2015.

Os efeitos da deficiência hídrica provavelmente provocaram o aumento de solos expostos, em detrimento a perda de vegetação que correspondeu a $41,8 \%$ no período analisado. Acrescenta-se que essa condição denota ao regime hidrológico dos canais estuarinos serem dominado por marés, e maior exposição das margens a possíveis eventos erosivos e de assoreamento.

A utilização de imagens LandSat-8, a partir da aplicação da álgebra de mapas para estimar os índices de vegetação através do SAVI, apresentou resultados satisfatórios. Portanto, a metodologia utilizada, por meio da integração da modelagem de dados para obtenção de balanço hídrico climatológico e da aplicação de técnicas de Processamento Digital de Imagens (PDI), são alternativas viáveis para estudos relacionados às variações temporais da cobertura vegetal, sobretudo em regiões de domínio semiárido. 


\section{REFERÊNCIAS}

AB'SÁBER, A.N. O domínio morfoclimático semiárido das caatingas brasileiras. São Paulo: USP-Instituto de Geografia, 1974.

ALVARENGA, A. S.; MORAES, M. F. Utilização de imagens LANDSAT - 8 para caracterização da cobertura vegetal. 2014. Disponível em $<$ http://mundogeo.com/blog/2014/06/10/processamento-digital-de-imagens-landsat-8-paraobtencao-dos-indices-de-vegetacao-ndvi-e-savi-visando-a-caracterizacao-da-cobertura-vegetal-nomunicipio-de-nova-lima-mg/>. Acesso em 26 de março de 2017.

AMARO, V.E.; MARCELINO, A.M.T.; VITAL, H.; RAMOS E SILVA, C.A.; CORTÊZ, A.A. Diagnóstico e Vulnerabilidade Ambiental dos Estuários do Litoral Norte e seus Entornos. In: Instituto de Desenvolvimento Econômico e Meio Ambiente do Rio Grande do Norte - IDEMA. Projeto Zoneamento Ecológico-Econômico dos Estuários do Estado do Rio Grande do Norte e seus Entornos, Natal/RN: SUGERCO/IDEMA, 2002. (Relatório Final).

AMARO, V.E.; COSTA, B.C.P. Identificação fitofisionômica através de imagens orbitais híbridas do LANDSAT5-TM e do RADARSAT-1 em manguezais do litoral setentrional do Rio Grande do Norte. Revista de Geologia, v.25, p. 115-127, 2012.

ANDRADE, R.; DEL'ARCO SANCHES, I.; VICTORIA, D.C.; FURTADO, A. L. Análise de metodologias para correção atmosférica e estimativa do albedo da superfícieusando imagens Landsat 5, TM. In: SIMPÓSIO DE GEOTECNOLOGIAS NO PANTANAL, 3., 2010, Cáceres. Anais... Campinas: Embrapa Informática Agropecuária; São José dos Campos: Inpe, 2010. p. 133141.

BERLATO, M.A.; MOLION, L.C.B. Evaporação e evapotranspiração, Porto Alegre: IPAGRO/Secretaria de Agricultura, 1981. (Boletim Técnico 7).

BRASIL. Lei $\mathrm{n}^{\circ}$ 12.651, de 25 de Maio de 2012. Dispõe sobre a proteção da vegetação nativa. Disponível em: <http://www.planalto.gov.br/ccivil_03/_ato2011-2014/2012/lei/112651.htm> Acesso em 19 junho de 2017.

CÂMARA G; SOUZA R.C.M.; FREITAS U.M.; GARRIDO J. SPRING: Integrating remote sensing and GIS by object-oriented data modelling. Computers \& Graphics, v. 20, p. 395-403, 1996.

CASTRO, A.F.; SOUTO, M.V.S.; AMARO, V.E.; VITAL, H. Desenvolvimento e aplicação de um banco de dados geográficos na elaboração de mapas da morfodinâmica costeira e sensibilidade ambiental ao derramamento de óleo em áreas costeiras localizadas no Estado do Rio Grande do Norte. Revista Brasileira de Geociências, v. 33, 2003. 
COSTA, D.F.S.; MEDEIROS, D.H.M.; DE MEDEIROS ROCHA, R. Breve revisão sobre a evolução histórica da atividade salineira no Estado do Rio Grande do Norte (Brasil). Rev. Sociedade \& Natureza, v. 25, p. $21-34,2013$.

COSTA, D.F.S.; GUEDES, D.R.C.; ROCHA, R.; BARBOSA, J.E.L.; SOARES, A.M.V.M.; LILLEBO, A.I. Influência de macroaspectos ambientais na produção de sal marinho no litoral semiárido do Brasil. Revista de Geografia (UFPE), v. 31, 2014.

COSTA, F.H.S.; PETTA, R.A.; LIMA, R.F.S.; MEDEIROS, C.N. Determinação da vulnerabilidade ambiental na Bacia Potiguar, região de Macau (RN), utilizando Sistemas de Informações Geográficas, Revista Brasileira de Cartografia, 2006.

DINIZ, M.T.M.; PEREIRA, V.H.C. Climatologia do estado do Rio Grande do Norte, Brasil: sistemas atmosféricos atuantes e mapeamento de tipos de clima. Bol. Goia. Geogr. (Online), v. 35, n. 3, p. 488-506, 2015.

DINIZ, M.T.M.; VASCONCELOS, F.P. Porque o nordeste produz sal marinho? Estudo analógico do potencial do clima. Caderno de Geografia, v.26, 2016.

FERREIRA, D.M.; MELO, J.V.; COSTA NETO, L.X. Influência da carcinicultura sobre a salinização do solo em áreas do município de Guamaré/RN. Holos, 2008.

GRIGIO, A.M.; AMARO, V.E.; DIODATO, M.A.; CASTRO, A.F. Determination of indices of multiple and Multiple Weighted Geodiversity of landscape of the Piranhas-Assu river, Rio Grande do Norte - Brazil. Journal of Coastal Research, p. 1668 - 1671, 2011.

HUETE, A.R. A soil-adjusted vegetation index (SAVI), Elsevier Science Publishing Co., New York, USA. 25:295-309, 1988.

INSTITUTO DE DESENVOLVIMENTO ECONÔMICO E MEIO AMBIENTE DO RIO GRANDE DO NORTE- IDEMA. Zoneamento Ecológico-Econômico dos Estuários do Estado do Rio Grande do Norte: estuário Galinhos-Guamaré/RN. Natal: IDEMA, 2002. (Relatório final). MAIA, R.P.; BEZERRA, F.H.R. Tectônica pós-miocênica e controle estrutural de drenagem no Rio Apodi-Mossoró, Nordeste do Brasil. Bol. Geogr., v.31, n.2, p.57-68, 2013.

MARENGO, J.A.; CUNHA, A.P.; ALVEZ, L.M. A seca de 2012-15 no semiárido do Nordeste do Brasil no contexto histórico. Revista Climanálise, 2016.

MEDEIROS, D.H.M.; CAVALCANTE; A.A.; PINHEIRO, L.S.; COSTA, D.F.S.; DE MEDEIROS ROCHA, R. Potencialidades naturais de ambientes hipersalinos para desenvolvimento socioeconômico: litoral setentrional do Rio Grande do Norte, Brasil. In: VIII Simpósio Latinoamericano de Geografia Física e IV Simpósio Iberoamericano de Geografia Física, 2014, Santiago. Anais... Santiago: Facultad de Arquitectura y Urbanismo - Universidad de Chile, 2014, p. 195-203. 
MEDEIROS, D.H.M. Ambientes hipersalinos no litoral semiárido brasileiro: zona estuarina do Rio Apodi - Mossoró (RN). Dissertação (Mestrado em Geografia) - Programa de Pós Graduação em Geografia. Universidade Estadual do Ceará, Fortaleza, 2016.

NIMER, E. Climatologia do Brasil. 2. ed. Rio de Janeiro: IBGE, 1989.

PINHEIRO, L.S. Riscos e Impactos Ambientais no Estuário do Rio Malcozinhado, CascavelCE. Recife, 2003. Tese (Doutorado em Oceanografia) - Universidade Federal de Pernambuco. PINHEIRO, L.S. \& MORAIS, J.O. Interferências de barramentos no regime hidrológico do Estuário do Rio Catú-Ceará-Nordeste do Brasil. Sociedade \& Natureza, Uberlândia, v. 22, n. 2, p. 237-250, ago. 2010.

PONZONI, F. J.; SHIMABUKURO, Y. E. Sensoriamento Remoto no Estudo da Vegetação. São José dos Campos: Parêntese, 2010.

PORTILHO, A.P.; CASTRO, M.C.; ALVES, G.S; AGUIAR, N.F.; SILVA, M.S. Balanço hídrico para Pinheral, Rio de Janeiro. Revista Agroambiental, v. 3, n. 2, p. 21-28, 2011.

RADAMBRASIL. Levantamento de Recursos Naturais/Geologia/Geomorfologia/Pedologia/Vegetação/Uso Potencial da Terra. Rio de Janeiro: Ministério das Minas e Energia, v. 23 - Folhas SB. 24/25 - Jaguaribe/Natal, 1981.

RAMOS E SILVA, C.A. (coord.). Caracterização física, físico-química e química dos estuários Apodi, Conchas, Cavalos, Açu, Guamaré, Galinhos, Ceará-Mirim, Potengi, Papeba e Guaraíra. Relatório final. Natal/RN: Instituto de Desenvolvimento Econômico e Meio Ambiente do Rio Grande do Norte/IDEMA, 50 p, 2004.

ROLIM, G.S.; SENTELHAS, P.C.; BARBIERI, V. Planilhas no ambiente EXCEL para os cálculos de balanços hídricos: normal, seqüencial, de cultura e de produtividade real e potencial. Revista Brasileira de Agrometeorologia, Santa Maria, v.6, p.133-137, 1998.

SCHETTINI, C.A.F.; VALLE-LEVINSON, A.; TRUCCOLO, E.C. Circulation and transport in short, low-inflow estuaries under anthropogenic stresses. Regional Studies in Marine Science, v. 10, p. 52-64, 2017.

SILVA, D.R.V.; AMARO, V.E. Integração entre dados ópticos e radar (SRTM) para a caracterização geoambiental da costa setentrional do Rio Grande do Norte. Rev. Geogr. Acadêmica, v.2, p. 111-123, 2008.

SOARES. C.H.C. Análise hidrodinâmica e morfodinâmica do complexo estuarino do Rio Piranhas-Açu/RN, Nordeste do Brasil. 2012. Dissertação (Mestrado em Geodinâmica e Geofísica) - Programa de Pós Graduação em Geodinâmica e Geofísica. Universidade Federal do Rio Grande do Norte, Natal, 2012. 
THORNTHWAITE, C.W.; MATHER, J.R. The water balance. Publications in Climatology. New Jersey: Drexel Institute of Technology, 1955.

TUCCI, C.E.M. Hidrologia: ciência e aplicação. 4. ed, Porto Alegre: Editora UFRGS/ABRH, 2007.

VIGANÓ, H.A.; BORGES, E.F.; FRANCA-ROCHA, W.S.S. Análise do desempenho dos Índices de Vegetação NDVI e SAVI a partir de imagem Aster. In: XV Simpósio Brasileiro de Sensoriamento Remoto - SBSR, Anais... Curitiba: INPE, 2011.

VALENTIM, S.S. Importância do balanço hídrico na circulação de um estuário do semiárido: o estuário o rio Coreaú (NW/Ceará/Brasil). Fortaleza, 2016. Tese (Doutorado em Ciências Marinhas Tropicais). Programa de Pós Graduação em Ciências Marinhas Tropicais. Universidade Federal do Ceará.

VALLE-LEVINSON, A. \& SCHETTINI, C.A. Fortnightly switching of residual flow drivers in a tropical semiarid estuary. Estuarine, Coastal and Shelf Science, v. 169, p. 46 - 55, 2016.

\section{AGRADECIMENTOS}

Ao Programa de Pós-Graduação em Ciências Marinhas Tropicais - PPGCMT/UFC e a Coordenação de Aperfeiçoamento de Pessoal de Nível Superior - CAPES, pela concessão da bolsa de doutorado para o primeiro autor. Ao $\mathrm{CNPq}$ pela bolsa de produtividade em pesquisa para segunda autora. As instituições INMET, INPE e USGS pela disponibilização gratuita dos dados para a realização do trabalho.

Recebido em: 15/08/2018

Aceite para publicação em: 05/11/2018 